\begin{tabular}{l} 
MIMESIS \\
Universitas \\
Ahmad Dahlan \\
VOL. 3. No. 1, Januari 2022 \\
\hline
\end{tabular}

\title{
KARAKTERISTIK KEBAHASAAN TOKOH PEREMPUAN DAN LAKI-LAKI DALAM FILM PENDEK
}

\section{Via Cahyani}

Magister Linguistik

Fakultas Ilmu Budaya,_Universitas Gadjah Mada

viacahyani@gmail.ugm.ac.id

\section{Tristanti Apriyani}

Sastra Indonesia

Fakultas Sastra, Budaya, dan Komunikasi,_Universitas Ahmad Dahlan tristanti.apriyani@idlitera.uad.ac.id

\section{Article history}

Received 13 January 2022

Revised 28 January 2022

Accepted 29 January 2022

Keywords

Language

Gender

Short film
Research is motivated by the differences in the language used by men and women. Environmental factors and society assume that women are gentle creatures, causing women to be careful about the choice of words in speech. Characteristics of women's language coined by Lakoff (1975) became a reference in this study. The problem discussed in this research is how the characteristics of women's language in the short film Reunian and the characteristics of men's language in the short film Dodit Not Penculik. This study aims to describe the linguistic characteristics of women and men in the two short films. The method used in this paper is descriptive qualitative, and quantitative with the subject of the short film Reunian and the short film Dodit Not The Kidnapper. The data acquisition in this study used the method of observing the free-engagement technique and the note-taking technique. Then the analysis in this study is that women tend to be unsure of their speech because women are very concerned about social norms and protect their self-esteem by using more polite speech.

This is an open access article under the CC-BY-SA license.
Article history

Received 13 Januari 2022

Revised 28 Januari 2022

Accepted 29 Januari 2022

Keywords

Bahasa

Gender

Film Pendek
Penelitian ini dilatarbelakangi oleh perbedaan bahasa yang digunakan oleh laki-laki dan perempuan. Faktor lingkungan dan masyarakat yang beranggapan bahwa perempuan adalah makhluk yang lembut sehingga menyebabkan perempuan harus berhati-hati terhadap pemilihan kata dalam tuturan. Karakteristik kebahsaan perempuan yang dicetuskan oleh Lakoff (1975) menjadi acuan dalam penelitian ini. Masalah yang dibahas dalam penelitian ini adalah bagaimana karakteristik kebahasaan perempuan dalam film pendek Reunian dan karakteristik kebahasaan laki-laki dalam film pendek Dodit Bukan Penculik. Penelitian ini bertujuan untuk mendeskripsikan apa saja karakteristik kebahasaan perempuan dan laki-laki dalam kedua film pendek tersebut. Metode yang digunakan dalam penelitian ini adalah mix method dengan teknik pemerolehan data yang menggunakan metode simak teknik bebas libat cakap, dan teknik catat. Hasil penelitian menunjukkan bahwa perempuan cenderung tidak yakin dengan tuturannya yang disebabkan karena perempuan sangat memperhatikan norma sosial dan melindungi harga dirinya dengan menggunakan tuturan yang lebih santun. 


\begin{tabular}{|c|c|c|}
\hline $\begin{array}{l}\text { UAD } \\
\text { Universitas } \\
\text { Ahmad Dahlan }\end{array}$ & $\begin{array}{c}\text { MIMESIS } \\
\text { VoL. 3. No. 1, Januari } 2022\end{array}$ & \\
\hline
\end{tabular}

\section{PENDAHULUAN}

Bahasa adalah struktur dan makna yang bebas dari penggunaannya, sebagai tanda yang menyimpulkan suatu tujuan (Rasyid et al., 2009, p. 126). Penyampaian bahasa bisa dilakukan melalui lisan, tulisan, maupun gerakan atau gesture (Putra, 2016 :43). Manusia menggunakan bahasa untuk berkomunikasi agar pesan yang ingin disampaikan dapat diterima dengan baik oleh lawan tuturnya. Bahasa akan terus berubah-ubah dan berkembang seiring perkembangan zaman. Bahasa yang digunakan oleh manusia tentunya bervariasi di setiap kelompok masyarakat, hal ini disebabkan karena bahasa selalu berhubungan erat dengan faktor sosial, situasional, dan kultural. Oleh karena itu Wardhaugh \& Fuller (Wardhaugh \& Fuller, 2015) yang juga dikutip Wijana \& Rohmadi (2011: 18) mengatakan bahwa komunitas yang tidak homogen merupakan penyebab dari keterkaitan bahasa dengan faktor kemasyarakatan.

Penggunaan kebahasaan pada gender yang berbeda sangat dipengaruhi oleh faktor sosial dan budaya. Secara sosial kebahasaan laki-laki dan perempuan terbentuk karena adanya status sosial yang melekat pada perempuan dan menegaskan secara ideologi bahwa posisi laki-laki lebih jelas dan adanya peran sosial yang berbeda antara laki-laki dan perempuan menegaskan bahwa perempuan dipandang sebagai makhluk yang lenih mengutamakan sisi emosionalnya, serta sangat bergantung kepada orang lain. Sementara itu, secara budaya penggunaan kebahasaan laki-laki dan perempuan terbentuk karena adanya anggapan bahwa pria lebih unggul dari perempuan dan ideologi gender yang menyebabkan perbedaan pandangan terhadap kedua gender tersebut khususnya dari segi linguistik.

Harimasyah (2011: 143) menjelaskan aspek variasi pemilihan bahasa untuk menunjukkan hubungan bahasa dan masyarakatnya, antara lain berdasarkan usia, kelas soial, pendidikan, etnik, kelompok sosial, bahkan gender atau jenis kelamin. Showalter dalam Umar (2010: 30) mengatakan bahwa gender lebih dari sekedar perbedaan laki-laki dan perempuan, tapi juga dilihat dari konstruksi sosial budayanya yang berkaitan dengan sifat, status, posisi, dan perannya dalam masyarakat. Istilah gender jika dilihat dari sosiolinguistik merupakan variasi pemilihan bahasa antara laki-laki dan perempuan yang berkaitan dengan situasi masyarakat. Perbedaan gender jelas sangat berpengaruh terhadap bentuk tuturan yang digunakan, pilihan kata dan cara atau gaya berbicara sangat berpengaruh ketika seseorang bertutur kata (Wardhaugh \& Fuller, 2015: 315).

Menurut penelitian linguistik perempuan terkadang tidak dipakai sebagai informan karena alasan tertentu. Perempuan cenderung memiliki sifat hypercorrect sehingga kerap mengaburkan situasi yang diinginkan para peneliti. Selain itu perempuan juga dianggap sebagai warga negara "kelas dua" (Sumarsono, 201: 499) yang memaksa perempuan untuk meningkatkan derajatnya hingga setara dengan laki-laki. Cara yang paling mudah dan efektif adalah dengan memperbaiki pemilihan kebahasaan.

Menurut Lakoff (1975: 8) terdapat beberapa karakteristik kebahasaan yang digunakan oleh perempuan, diantaranya color words, empty adjectives, question intonation, hedge, intensifier, hypercorrect grammar, super polite form, tag questions, avoidance of swear words, serta emphatic stress. Lakoff (1975: 8) beranggapan bahwa perempuan memiliki sifat yang lebih teliti dan detail dibanding laki-laki. Hal ini dapat dibuktikan pada perbedaan penyebutan dan kosa kata warna (color words) antara laki-laki dan perempuan. Pemilihan kata sifat kebih banyak digunakan olek perempuan dibandingkan dengan laki-laki (Lakoff, 1975: 53). Kata sifat yang di maksud di sini adalah kata sifat yang digunakan untuk mengungkapkan ekspresi kagum terhadap sesuatu (empty adjectives). Kebanyakan perempuan menggunakan intonasi (question intonation) ketika bertanya atau menjawab suatu pertanyaan. Pola intonasi yang digunakan adalah intonasi tinggi seperti pola pertanyaan yes-no question. Perempuan pun 


\begin{tabular}{l} 
MADESIS \\
Universitas \\
Ahmad Dahlan \\
VoL. 3o. 1, Januari 2022 \\
\hline
\end{tabular}

cenderung menggunakan ungkapan yang menunjukkan bahwa mereka merasa tidak begitu yakin dengan perkataannya (hedge) seperti ungkapan well, you know, kinda, I guess, I think dan lain lain (Hanna, 2012). Brown \& Levinson (1987: 134) berpendapat jika dilihat dari sisi kesantunan tuturan atau ungkapan terkesan tidak langsung atau "kasar".

Karakteristik pemilihan bahasa perempuan disebabkan karena tuturan perempuan dianggap memiliki hubungan yang dengan sisi emosional dan penggunaan "penyagat" atau kata keterangan dimaksudkan untuk memberikan kesan penekanan terhadap kata sifat, kata kerja atau kata keterangan lain (intensifier). Perempuan pun cenderung menggunakan bahasa baku (hypercorrect grammar) dan perempuan dinilai lebih memiliki tuturan yang lebih sopan dibandingkan dengan laki-laki (Holmes, 2013: 318). Lakoff (Lakoff, 1975: 55) menganggap bahwa bentuk ungkapan atau tuturan yang sangat santun sudah sepantasnya digunakan oleh perempuan (super polite form). Selain itu perempuan juga dianggap harus sering menggunakan ungkapan seperti, mohon, tolong, terima kasih agar tetap menjaga konvensi sosial.

Ungkapan yang terdapat di akhir kalimat (Tag question) digunakan perempuan jika ia merasa kurang yakin dengan tuturannya dan tuturan tersebut diungkapkan agar terkesan santun (Lakoff, 1975: 15). Perempuan pun menggunakan ungkapan yang memberikan kesan penekanan terhadap sebuah kalimat yang dituturkan dan dijadikan cara untuk menghina sesuatu atau seseorang (Avoidance of strong swear words). Sementara itu, untuk memberikan penekanan terhadap suatu tuturan agar lawan tuturnya merasa yakin dengan apa yang disampaikannya, perempuan menggunakan ekspresi kurang yakin (Emphatic stress).

Kajian tentang karakteristik bahasa tulis dengan menggunakan teori Lakoff pernah dilakukan Fitriyani et al., (2019) dan Febriani (2021). Fitriyani et al., (2019) mengkaji ekspresi bahasa Indonesia tulis berdasarkan gender pada media facebook. Dikatakan bahwa laki-laki mencerminkan sisi maskulinitasnya berupa kekuatan fisik, altruisme, kepemimpinan, kegiatan outdoor dll. Facebooker laki-laki lebih cenderung menggunakan bahasa daerah dan bahasa asing dalam mengunggah status dibandingkan facebooker perempuan. Febriani (2021) menemukan tokoh perempuan dalam novel Suluk Mu'tazilah karya Hasnan Singodimayan menggunakan bahasa untuk menetapkan, memelihara dan mengembangkan hubungan pribadi, sedangkan lelaki cenderung melihat bahasa yang lebih sebagai alat untuk memperoleh informasi yang tersampaikan.

Karakteristik kebahasaan perempuan bisa dilihat melalui sebuah film seperti yang telah diteliti Hidayati (2016) dan Hasanah \& Wicaksono (2021). Meski kedua penelitian tersebut sama-sama menggunakan teori Lakoff, namun objek penelitian keduanya berbeda dengan penelitian ini. Penelitian ini bertujuan untuk mengkaji karakteristik kebahasaan tokoh perempuan dalam film pendek Reunian dan karakteristik kebahasaan tokoh laki-laki di dalam Film pendek Dodit Bukan Penculik. Film pendek merupakan film yang durasinya tidak lebih dari 60 menit. Reunian merupakan salah satu film pendek yang para tokoh di dalamnya adalah perempuan. Film ini diproduksi oleh Kementrian Pendidikan dan Kebudayaan Republik Indonesia Direktorat Jendral Pendidikan Vokasi pada tahun 2020, yang diunggah pada channel youtube Wikan-Sakarinto. Sementara itu, film Dodit Bukan Penculik merupakan film pendek bergenre komedi yang diunggah channel youtube Hajar Pamuji pada tahun 2020 yang menampilkan tokoh utama laki-laki.

\section{METODE}

Penelitian ini menggunakan metode mix methods yang menggabungkan dua pendekatan dalam sebuah penelitian yaitu kualitatif dan kuantitatif (Creswell, 2014: 5). Menurut Sugiyono (Sugiyono, 2014) seperti yang dikutip Apriyani (2020: 109) menyatakan bahwa mix methods 


MIMESIS
Und. 3. No. 1, Januari 2022
Universitas
Ahmad Dahlan

merupakan metode penelitian yang menggabungkan antara dua metode kualitatif dan kuantitatif dalam sebuah kegiatan penelitian, dengan tujuan agar data yang diperoleh lebih komprehensif, valid, reliabel, dan objektif. Metode kualitatif digunakan untuk mengkaji bentuk karakteristik kebahasaan dalam tuturan tokoh perempuan pada film pendek Reunian dan Dodit Bukan Penculik. Metode kuantitatif digunakan untuk menghitung perbandingan karakteristik kebahasaan perempuan dan laki-laki paada kedua film pendek tersebut.

Pengumpulan data dalam analisis ini menggunakan metode simak teknik bebas libat cakap, dan teknik catat. Metode simak digunakan untuk menggali data dari sumber data. Data yang diperoleh dengan menyimak video dari youtube dan mengabadikan dengan cara mencatatnya. Data dalam penelitian ini adalah film pendek Reunian dan Dodit Bukan Penculik.

\section{PEMBAHASAN}

Ditemukan 26 data pada film pendek Reunian dan 21 data pada film pendek Dodit Bukan Penculik yang termasuk dalam karakteristik bahsa permpuan menurut Lakoff (1975) diantaranya empty adjectives, question intonation, hedge, intensifier, super polite form, tag questions dan avoidance of swear words. Dalam Film pendek berjudul Reunian ini tidak ditemukan tuturan tokoh perempuan yang menunjukka karakteristik color words, hypercorrect grammar, avoidance of swear words, dan Emphatic stress. Sedangkan dalam Film pendek berjudul Dodit Bukan Penculik tidak ditemuakan color words, question intonation, hypercorrect grammar, dan Emphatic stress.

Temuan data karakteristik kebahasaan yang dikemukakan oleh Lakoff(1975) dalam film pendek Reunian dan Dodit Bukan Penculik adalah sebagai berikut.

Tabel 1. Perbandingan karakteristik kebahasaan

\begin{tabular}{|c|l|l|l|}
\hline \multirow{2}{*}{ No } & \multirow{2}{*}{ Karakteristik kebahasaan } & \multicolumn{2}{|c|}{ Film Pendek } \\
\cline { 3 - 4 } & & Reunian & Dodit Bukan Penculik \\
\hline 1 & Color words & - & - \\
\hline 2 & Empty adective & $4(67 \%)$ & $2(33 \%)$ \\
\hline 3 & Questions intonation & $2(100 \%)$ & - \\
\hline 4 & hedge & $6(67 \%)$ & $3(33 \%)$ \\
\hline 5 & intensifier & $5(50 \%)$ & $5(50 \%)$ \\
\hline 6 & Hypercorrect grammar & - & - \\
\hline 7 & Super polite form & $3(50 \%)$ & $3(50 \%)$ \\
\hline 8 & Tag Questions & $15(88 \%)$ & $2(12 \%)$ \\
\hline 9 & Advoidance of strong swear & - & $6(100 \%)$ \\
\hline 10 & Emphatic stress & - & - \\
\hline \multicolumn{2}{|c}{ Jumlah } & 26 & 21 \\
\hline
\end{tabular}

\section{Empty adjectives}

Karakteristik empty adjective merupakan pemilihan kata sifat yang digunakan oleh perempuan untuk menunjukkan kekaguman.

Film pendek Reunian 
Pada film pendek Reunian ditemukan 4 data yang menunjukkan karakteristik empty adjectives yakni pada kata "senengnya" "ayu", dan "seru".

"Ih Ya Allah, senengnya."

"Wiwit tambah ayu aja."

(Wiwit, tambah cantik saja)

"Alhamdulillah, ibu seneng banget dengernya."

"Wah ya seru banget. Kan lama ngga ketemu."

Kata "senengnya", "ayu" (cantik), "seneng", dan "seru" merupakan kata yang diucapkan oleh tokoh untuk menunjukkan kekagumannya pada seseorang atau sesuatu, secara tidak langsung hal ini menunjukkan bahwa perempuan suka memuji dan suka dipuji. Selain itu masyarakat juga menilai semakin banyak empty adjectives yang dituturkan oleh perempuan maka semakin santun tuturannya.

\section{Film pendek Dodit Bukan Penculik}

Pada film pendek Dodit Bukan Penculik ditemukan 2 data yang menunjukkan karakteristik empty adjectives yakni pada kata "hebat".

"Hebat, Lek! Jos"

"Kang Dodit hebat main gitare!"

(Kang Dodit hebat memainkan gitarnya)

Kata "hebat" pada data tersebut juga digunakan tokoh untuk menunjukkan kekagumannya pada seseorang atau sesuatu. Pada temuan penelitian ini laki-laki lebih sedikit menggunakan empty adjectives dari pada perempuan ketika berbicara. Hal ini menunjukkan bahwa laki-laki cenderung berbicara sesuai dengan bagaimana fakta yang ada.

\section{Question intonation}

Karakteristik question intonation kerap digunakan perempuan untuk menjawab pertanyaan dengan pola intonasi yang seperti pertanyaan juga, hal ini disebabkan karena mereka kurang yakin dengan pernyataan mereka.

\section{Film pendek Reunian}

Ditemukan 2 data yang menunjukkan karakteristi question intonation pada film pendek Reunian.

A: "Gimana kabarnya?"

B: "Alhamdulillah sehat, ya namanya juga pandemi (Covid-19) ya? Sebenernya aku juga takut loh pergi-pergi kaya gini."

Pertanyaan A dijawab oleh B dengan intonasi pertanyaan juga. Hal ini menunjukkan bahwa B kurang yakin dengan penyataannya, bahwa dalam kondisi pandemi seperti sekarang walaupun keadaan B sehat tetapi B harus tetap berhati-hati agar tidak terkena Covid.

\section{Film pendek Dodit Bukan Penculik}

Karakteristik question intonation tidak ditemukan dalam film pendek Dodit Bukan Penculik. Hal ini menunjukkan bahwa laki-laki lebih percaya diri atau yakin dengan apa yang dikatakannya.

\section{Hedge}

Karakteristik hedge digunakan oleh perempuan ketika mereka merasa kurang yakin dengan perkataannya. 


\section{Film pendek Reunian}

Terdapat 6 perkataan dalam film pendek "Reunian" yang menunjukkan karakteristik hedge yakni pada kata "menurutku", "katanya", dan "kayanya".

"Ini kalo menurut aku sih ya, kalo menurut aku Rani itu sebenernya lagi fokus aja ke karir dia, makanya dia itu sampe sekarang belum nikah."

"Eh Jeng, mbok anakmu ngajakin anakku buat main film. Iya anakku tuh sekarang jadi model iklan gitu kebanyakan, katanya sih selebgram.

"Kayanya aku udah pernah kan dulu cerita sama kamu, kalo aku tuh ngga suka sama Bekti, tapi kamu sendiri kan yang ngga percaya."

Kata "menurut aku", "katanya", dan "kayanya" dituturkan oleh tokoh dalam film pendek ini bertujuan untuk menyatakan keragu-raguannya terhadap tuturannya. Dalam kata lain, tuturan yang dituturkannya belum tentu benar adanya. Perempuan juga menggunakan tuturan ini agar tuturannya terkesan tidak langsung dan lebih sopan.

\section{Film pendek Dodit Bukan Penculik}

Terdapat 3 perkataan dalam film pendek Dodit Bukan Penculik yang menunjukkan karakteristik hedge yakni pada kata "jare" dan "jarene".

"Jangan-jangan orang iki memang penculik. Wajahe wae wis ketoro. Bener jare

Lek Jon, gerak-gerike mencurigakan"

(jangan-jangan orang ini memang penculik. Wajahnya sudah kelihatam. Benar kata

Lek Jon, gerak geriknya mencurigakan)

"Dimas diculik karo penculik sing wong asing sing tak critake mau kok loh Lek, jarene malah digowo neng jawa timur kok!"

(dimas diculih oleh penculik yang aku ceritakan tadi, katanya akan dibawa ke Jawa Timur)

Kata "jare" dan "jarene" dituturkan oleh laki-laki dalam film ini bertujuan untuk menyatakan keragu-raguannya terhadap tuturannya. Pada penelitian ini karakteristik hedge lebih sering di tuturkan oleh perempuan daripada laki-laki. Namun, dalam hal ini laki-laki menuturkan karakteristik hedge cenderung karena ia kurang yakin dengan tuturannya.

\section{Intensifier}

Nama lain intensifier adalah 'penyengat' karakteristik ini digunakan perempuan untuk memberi tekanan pada kata sifat, kata kerja atau kata keterangan lain.

\section{Film pendek Reunian}

Ditemukan 5 data yang menunjukkan karakteristik intensifier yakni pada kata "banget" dan "harusnya".

"Maaf banget yah, aku telat. Aduh ya ampun tadi tuh aku banyak banget meeting yang harus aku ikutin."

Kata "banget" diucapkan untuk memberi penekanan pada kata "maaf", hal ini dituturkan agar penutur terkesan bersungguh-sungguh meminta maaf kepada lawan tuturnya karena ia terlambat datang.

\section{Film pendek Dodit Bukan Penculik}

Ditemukan 5 data yang menunjukkan karakteristik intensifier yakni pada kata "Ekstra", "ra karuan", dan "harus".

"dikongkon sediluk kok angele ra karuan!" 
(disuruh sebentar kok susah sekali)

"Ra karuan" dalam tuturan ini diucapkan untuk memberi penekanan pada kata "angel" (susah). Penekanan tersebut dituturkan karena penutur ingin menunjukan bahwa lawan tuturnya memang benar-benar susah diperintah walaupun hanya sebentar saja. Pada temuan ini laki-laki dan perempuan sama-sama kerap meggunakan intensifier ketika berbicara.

\section{Super Polite Form}

Karakteristik super polite form dianggap sudah sepantasnya diucapkan oleh perempuan agar terkesan santun.

\section{Film pendek Reunian}

Terdapat 3 data yang menunjukkan karakteristik super polite form yakni pada kata "sorry", "maaf", dan "hati-hati".

"Eh sorry yah, aku agak telat dikit tadi soalnya aku nunggu isya dulu."

"Maaf banget yah, aku telat. Aduh ya ampun tadi tuh aku banyak banget meeting yang harus aku ikutin."

"Hati-hati ya Rani ya."

Kata "sorry", "maaf", dan "hati-hati" dituturkan perempuan agar terkesan santun dan menghormati lawan tuturnya, dalam hal ini perempuan dianggap makhluk yang lembut yang sudah sepantasnya berbicara atau berperilaku santun terhadap orang lain.

\section{Film pendek Dodit Bukan Penculik}

Terdapat 3 data yang menunjukkan karakteristik super polite form yakni pada kata "tulung" dan "suwon".

"wis ngene Wen, iki mumpung ono koe Wen. Aku njaluk tulung a"

(sudah begini saja Wen. Mumpung ada kamu Wen. Aku mau minta tolong lah)

"aku njaluk tulung, njaluk banyu."

(aku minta tolong, minta air)

"suwon yo"

(terima kasih ya)

Kata "tulung" dan "suwon" juga dituturkan oleh laki-laki agar terkesan santun dan menghormati lawan tuturnya. Meskipun laki-laki dan perempuan sama sama kerap menuturkan super polite form, tapi stigma masyarakat terhadap kesopanan laki-laki tidak seperti pandangan mereka terhadap perempuan, bahwa perempuan harus berbicara atau berperilaku santun terhadap orang lain.

\section{Tag Questions}

Karakteristik tag questions digunakan perempuan karena mereka merasa kurang yakin terhadap tuturannya. Penggunaan tag questions juga untuk memberi kesan lebih santun.

\section{Film pendek Reunian}

Ditemukan 15 data yang menunjukkan karakteristik tag questions, yakni "Iya kan?”, “kan?”, "gampang kan?”, "gitu kan?”, “iya ngga sih?”, dan "ya kan Ayu?”. 
"Nih aku kasih tau, denger-denger pemerintah akan menerapkan kebiasaan baru $100 \%$ mulai bulan depan. Jadi kita bisa ngadain acara di bulan depan nih kalo mau, ya kan?"

"Ini kenapa pada ngomongin Rani sih jadinya? Haduh, eh Rani itu ngga kaya yang kamu pikirin loh, Wit. Secara dia itu udah punya jabatan yang bagus banget, iya kan?"

"Eh itu aja, ditawarin sama si Rani, dia kan sekarang jadi manager, kan?"

"Ih kan udah kebiasaan dia dari dulu. Ngerebut sana, ngerebut sini. Ngerebut sana ngerebut sini. Kaya gitu kan?"

"Lagian kita loh yang bakal inisiatif menyelenggarakan acara ini, kalo cowo-cowo mana mungkin, iya ngga sih?"

"Dan aku, juga ini, apa, sponsor. Sponsor makanannya. Gampang, nanti kan bisa tak mintain itu sama suamiku, gampang kan?"

"Ya udah deh kalo emang pilihan hidupnya kaya gitu dan terbaik buat dia ya kita doain aja semoga itu yang terbaik, ya kan Ayu?"

Penggunaan "Iya kan?”, “kan?”, “gampang kan?”, “gitu kan?”, “iya ngga sih?”, dan "ya kan Ayu?" Menunjukkan bahwa perempuan kurang yakin dengan tuturannya sehingga ketika perempuan berpendapat mereka akan meminta persetujuan atau meminta pendapatnya diyakinkan oleh lawan tutur agar mereka menjadi yakin. Selain itu karakteristik ini memberi kesan sopan karena perempuan cenderung memastikan pendapat yang mereka katakan disetujui oleh lawan tuturnya.

\section{Film pendek Dodit Bukan Penculik}

Ditemukan 2 data yang menunjukkan karakteristik tag questions, yakni "Priangan ta?" dan "iyo to?"

"Wong ndek SD aku diajari guruku nyanyi kok "halo halo Bandung, ibuk kota Priangan". Priangan ta?"

(waktu SD aku diajarkan nyanyi oleh guruku, "halo halo Bandung, ibuk kota Priangan", Priangan kan?)

"Heh koe penculik, iyo to?"

(heh kamu penculik, iya kan?)

Penggunaan "Priangan ta?" dan "iyo to?" pada tuturan tersebut menunjukkan bahwa penutur kurang yakin dengan tuturannya. Pada temuan ini tag questions paling banyak ditemukan pada tuturan perempuan daripada laki-laki. Hal ini disebabkan karena laki-laki cenderung lebih yakin dengan apa yang dituturkannya sedangkan perempuan cenderung meminta diyakinkan oleh lawan tuturnya apabila mereka kurang yakin terhadap tuturannya.

\section{Avoidance of Swear Words}

Karakteristik avoidance of swear words digunakan perempuan untuk memberikan kesan penekanan terhadap sebuah kalimat yang dituturkan dan dijadikan sebagai cara untuk menghina sesuatu atau seseorang.

\section{Film pendek Reunian}

Tidak ditemukan data yang menunjukkan karakteristik avoidance of swear words yakni pada tuturan perempuan. 


\section{Film pendek Dodit Bukan Penculik}

Ditemukan 5 tuturan yang menunjukkan karakteristik avoidance of swear words yakni "aduh".

"wooo, telek uwong. Mbok kiro aku iki pengamen!"

(wooo, tahi, kamu kira aku pengamen!)

"bodo ra karuan koe"

(bodoh sekali kamu)

"Lek Lek Lek, mbahmu wi!"

"Gitar mbahmu! Skincare!"

"dasar, wong edan!"

(dasar, orang gila!)

"cangkeman, berisik!"

(banyak omong, berisik!)

Penggunaan kata "telek uwong", "bodo", "mbahmu", "wong edan", dan "cangkeman" oleh tokoh laki-laki pada tuturan tersebut ditujukan untuk menekan terhadap sesuatu yang sedang dihina atau dikeluhkannya. Pada temuan penelitian ini perempuan lebih memilih mengunakan kata-kata yang lebih santun untuk menghina atau mengeluhkan seuatu, sedangkan laki-laki cenderung menggunakan kata-kata makian atau kasar.

\section{KESIMPULAN}

Berdasarkan hasil penelitian ditemukan data yang paling dominan adalah pada karakteristik tag questions, yakni sebanyak 15 (83\%) data pada film pendek Reunian sedangkan dalam film pendek Dodit Bukan Penculik karakteristik ini merupaka data yang peling sedikit, yakni $2(12 \%)$ data. Secara tidak langsung hal ini menunjukkan bahwa perempuan memiliki sifat alamiah untuk diyakinkan tuturannya ketika mereka berpendapat sedangkan laki-laki cenderung lebih yakin dengan apa yang dituturkannya. Selanjutnya perempuan sangat memperhatikan norma sosial dan melindungi harga dirinya dengan menggunakan tuturan yang lebih santun. Selain itu, perempuan sangat berhati-hati dalam memilih tuturan yang ditujukan untuk menghina atau mengeluh. Selain itu, masyarakat cenderung menganggap lumrah dan memaklumi ketika laki-laki menuturkan tuturan makian atau kasar, sedangkan masyarakat tidak dapat memaklumi hal yang sama dari perempuan. Dapat dikatakan bahwa perempuan boleh meluapkan amarahnya, tapi dengan menggunakan bahasa yang santun.

\section{DAFTAR PUSTAKA}

Apriyani, T. (2020). Pembelajaran sastra populer berbasis wattpad sebagai upaya peningkatan kemampuan literasi baca tulis. Suar Betang, 15(1), 107-116. https://doi.org/10.26499/surbet.v15i1.152

Brown, P., \& Levinson, S. C. (1987). Politeness: some universals in language usage (studies in interactional sociolinguistics 4). In Cambridge University Press. https://doi.org/10.2307/3587263

Creswell, J. W. (2014). Research design: pendekatan kualitatif, kuantitatif, dan mixed. Pustaka Pelajar. 
Febriani, I. (2021). Representasi Bahasa Perempuan dalam Novel Suluk Mu'tazilah karya Hasnan Singodimayan. Jurnal Metabasa, 3(1), 10-17.

Fitriyani, I., Wilian, S., \& Yusra, K. (2019). Ekspresi Bahasa Indonesia Tulis berdasarkan Gender pada Media Facebook. LINGUA: Journal of Language, Literature and Teaching, 16(1), 137-156. https://doi.org/10.30957/lingua.v16i1.581

Hanna, H. E. F. (2012). Hedges movie dialogues in english: theoretical and practical aspects. The journal for Languages and Literature of the Faculty of Philosophy Univerzitet u ovom Sadu. The Journal for Languages and Literature of the Faculty of Philosophy Univerzitet u Ovom Sadu, 11, 177-192.

Harimansyah, G. (2011). "Diksi laki-laki dan Perempuan" dalam puisi-mutakhir indonesia (kajian sosiolinguistik-genderistik). Widyariset, 14(1), 143-152.

Hasanah, H., \& Wicaksono, N. H. (2021). Bahasa dan Gender: Karakteristik Kebahasaan Perempuan Jawa dalam Film "Tilik." Jurnal Budaya FIB UB, 2(1), 7-16. https://jurnalbudaya.ub.ac.id7

Hidayati, N. N. (2016). Bahasa dan Gender: Kajian Karakteristik Kebahasaanlaki-Laki dan Perempuan dalam Film Anak. AL HIKMAH Jurnal Studi Keislaman, 6(1), 9-32.

Holmes, J. (2013). An introduction to sociolinguistics. In The Modern Language Journal. Routledge. https://doi.org/10.2307/329116

Lakoff, R. T. (1975). Language and woman's place. Harper \& Row Publisher.

Rasyid, H., Mansyur, \& Suratno. (2009). Asesemen perkembangan anak usia dini. Multi Pressindo.

Sugiyono. (2014). Metode penelitian kuantitatif, kualitatif dan R\&G. Alfabeta.

Sumarsono. (2014). Sosiolinguistik. Pustaka Pelajar.

Umar, N. (2010). Argumen Kesetaraan Gender. Pustaka pelajar.

Wardhaugh, R., \& Fuller, J. M. (2015). An introduction to sosiolinguistics. Blackwell.

Wijana, I. D. P., \& Rohmadi, M. (2011). Sosiolinguistik: kajian teori dan analisis. Pustaka Pelajar. 